\title{
Extending the Life Time of a Nuclear Power Plant: Impact on Nuclear Liabilities in the Czech Republic
}

\author{
L. Havlíček
}

Nuclear power plant (NPP) operators have several basic long-term liabilities. Such liabilities include storage, treatment and disposal of radioactive waste generated at the operators' NPP, storage and management of nuclear fuel irradiated in the reactor of the operator's NPP ("spent fuel"), disposal of the spent fuel (SF) or residues resulting from spent fuel reprocessing. Last but not least, the operator is liable for decommissioning its nuclear facilities. If the operator considers extending the life time of its NPP or if the construction of a new NPP is being evaluated by an investor, an integral part of the economic evaluation must be a comprehensive assessment of future incremental costs related to the above-mentioned long-term liabilities. An economic evaluation performed by standard methods (usually NPV, alternatively real options) leads to a decision either to proceed with the project or to shelve it.

If the investor decides to go ahead with the project there can be an immediate impact on nuclear liabilities. The impact is not the same for all operator liabilities. Depending on the valid legislation and the nature of the liability, in some cases the extent of the liability must be immediately recalculated when a decision is made to proceed with the project, and the annual accrual of accumulated reserves / funds must be adjusted. In other cases, the change in liability is linked to the generation of additional radioactive waste or spent fuel. In the Czech Republic, responsibility for each of the nuclear liabilities is defined, as is the form in which the financial means are to be accumulated. This paper deals with the impact of NPP life time extension (alternatively NPP power up-rate or construction of a new NPP) on individual nuclear liabilities in the conditions of the Czech Republic.

Keywords: Nuclear liabilities, spent fuel, radioactive waste, storage, disposal, decommissioning, financing.

\section{Definition of nuclear liabilities}

Liability can be simply defined as the obligation to transfer economic benefits as a result of a past transaction or a past event. If we apply this principle to the operation of an NPP, together with other required attributes of liabilities (sufficient probability of the event, possibility to express the consequences in financial terms, enforceability), we can identify the following basic nuclear liabilities:

- Radioactive waste (RW) treatment, storage and disposal

- Spent fuel (SF) storage and management

- Disposal of SF or residues from SF reprocessing

- Decommissioning of nuclear facilities, i.e. NPP, RW treatment facilities, SF storages, etc.

The basic legislation in the Czech Republic is the Nuclear Act 18/1997 Coll., as amended. The Act strictly specifies the division of responsibilities (and therefore liability) in the back-end of the nuclear fuel cycle. The state has assumed responsibility for safe disposal of the RW and SF that is produced. On the other hand, the NPP operator remains liable for treating its RW (the main aim is volume reduction and transformation to a form suitable for disposal). RW is in fact usually processed continually or in short-term campaigns. If it is necessary to store RW before treatment, or in the event that the RW is not suitable for disposal in currently operated near-surface repositories and must be disposed of in a future deep geological repository, the operator is responsible for RW storage. The NPP operator is also responsible for SF storage until the moment it is declared to be RW by the operator and handed over to the state for disposal. The NPP operator is also fully liable for decommissioning its nuclear facilities after the end of their operation.
It is logical that the financial means have to be accumulated by the subject responsible for the particular liability. In the case of RW and SF disposal, financial means in the form of a nuclear fund are accumulated and controlled by the state, though the funding is basically sourced from the prescribed contributions from the waste producers, including NPP operators. However, it is the operator who accumulates the funds for RW + SF storage and for decommissioning.

Although the liabilities will be settled in the distant future, many years after closure of the NPP, it is necessary to accumulate necessary financial funds while NPP is still in operation and to invest them continuously and safely in order to compensate the effects of inflation and to get at least some real yield over inflation. When the unit cost of current production is calculated, many different assumptions must be taken in account.

\section{Operator actions with an impact on nuclear liabilities}

When we analyze how liabilities are defined and calculated, we can list the following events that have a substantial influence on a financial expression of liability:

- Changes in production of SF and RW (changes on the costs side)

- Changes in storage, disposal, decommissioning technologies (costs side)

- Changes in electricity generated (revenue side)

- Changes in the time-schedule of future expenditures (influence on yield interest from invested funds)

- Changes in the economic environment and related factors, e.g., cost escalation, influence of inflation, yield from invested funds 
- Changes in legislation - redefinition of responsibilities, changes in the form of fund accumulation, enlargement or limitation of investment opportunities.

If the operator decides to extend the life time of its NPP, there will be a combination of the above-mentioned effects the volume of SF and RW is increased, the timing of the expenditures is changed and the amount of electricity to be generated is increased. If the operator (or potentially any investor) decides to build a new NPP, the effect on liabilities will in principle be the same, though the effect will be more pronounced. In addition, there are other projects with a potential impact on nuclear liabilities. The operator may decide to up-rate the installed capacity of its current NPP for the remaining part of the (unchanged) planned life time. These operator actions with an impact on nuclear liabilities are summarized in Fig. 1. Below, I will analyze the impact on individual nuclear liabilities.
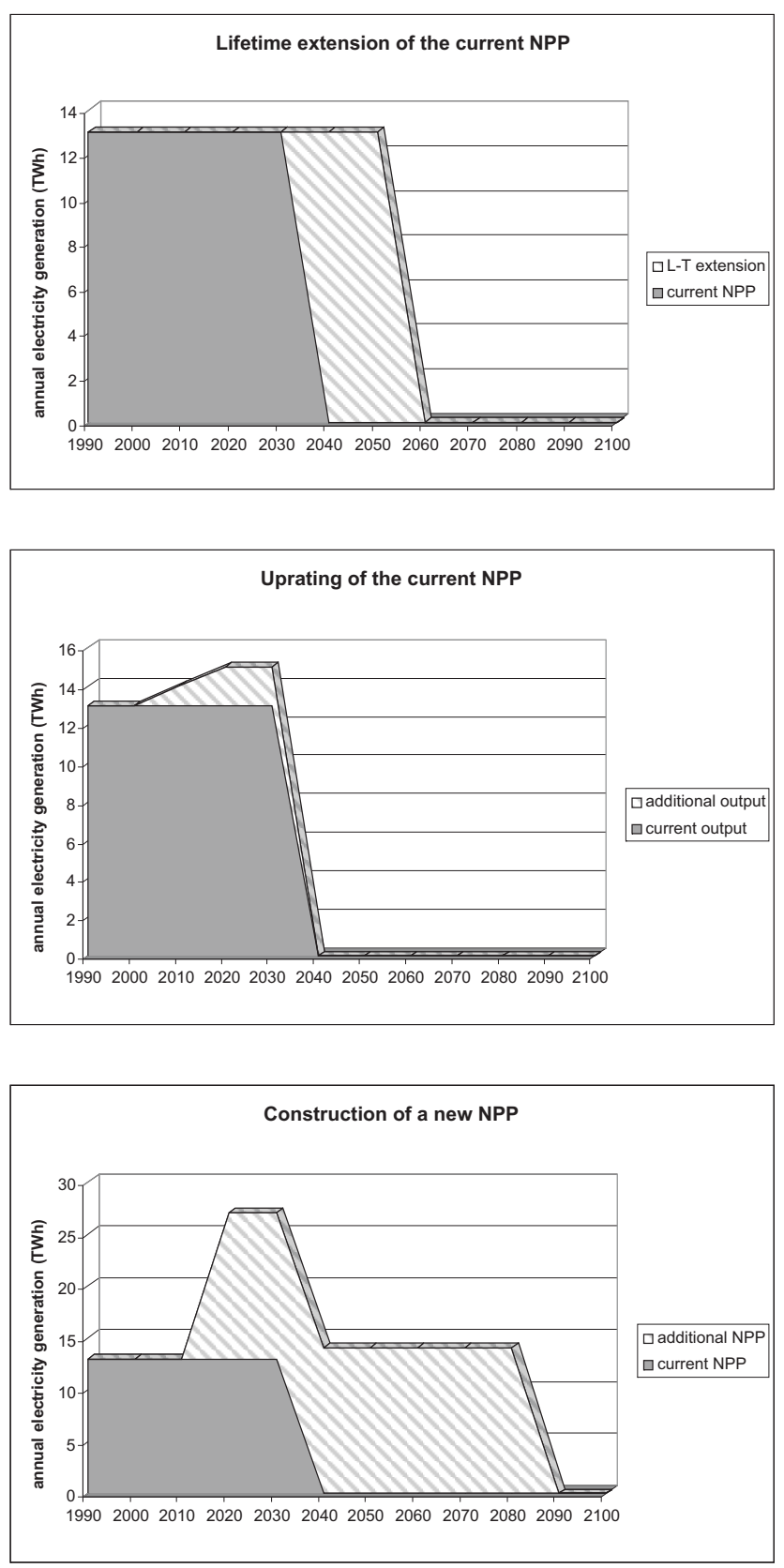

Fig. 1: Basic operator actions influencing nuclear liabilities
If we take the current situation in the Czech Republic, several such operator actions are being implemented or considered. The installed capacity at NPP Dukovany is being increased by means of turbine and control system modifications, and similar measures will be applied at NPP Temelín. As the fuel at NPP Dukovany has been improved substantially and is now able to support higher output with an unchanged 5 -year fuel cycle, there is no obvious impact on the cost side, and only the revenue side (the amount of electricity generated) will be increased.

In future the operator may decide to change the technology for storage of SF or to reprocess and recycle its SF in the reactor and dispose of only separated high-level waste. In such cases there would also be a substantial change in the operator's liability. As the current stage of technological development and the economics of reprocessing are not favorable, some fundamental change in the fuel cycle back-end strategy in the Czech Republic is not foreseen in the near future.

\section{Aspects of liability}

In principle, the basic considerations are as follows:

- INVESTOR'S VIEW - an investor needs to know if the project (i.e. an extension/up-rate/new build) will be efficient. Standard analytical methods like net present value (NPV) can be used. Costs per unit of future/additional production (e.g. MWh) connected with any particular liability can be calculated for the NPV enhancement feature.

- SHAREHOLDER'S VIEW - any change in liability must be correctly quantified in the operator's calculations. Only then can the current or potential shareholders base their decision on correct assumptions.

- REGULATOR'S (STATE'S) VIEW - the role of the state/regulator is to monitor whether sufficient funds for future expenditures are being generated and set aside.

\section{Options for model calculations}

Let us assume an NPP that has been in operation since the 1980 s. The currently planned life time is 40 years. The operator considers extending the life time by 10 or 20 years. This leads to the following options in Table 1.

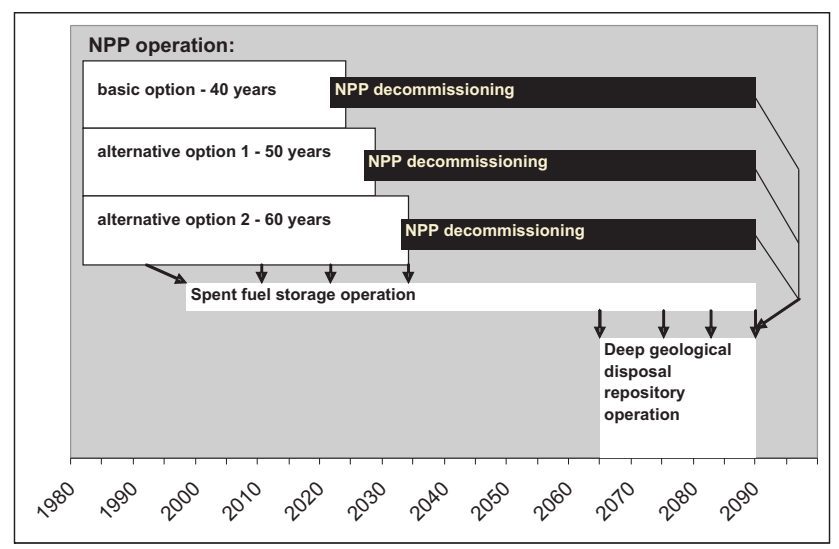

Fig. 2: Options for extending the current life time of NPP, and the connected time schedule 
Table 1: Definition of the options for extending the life time of NPP

\begin{tabular}{|c|c|c|c|}
\hline & basic option & Option 1 & Option 2 \\
\hline extension & 0 & 10 & 20 \\
\hline total life time & 40 & 50 & 60 \\
\hline
\end{tabular}

\section{Impact on individual liabilities}

\subsection{Spent fuel \& radioactive waste storage}

As was mentioned above, in the Czech Republic SF and RW storage is a liability of the NPP operator. The operator is required to cover not only all future costs connected with storage process itself, but also costs related to transport from the reactor to the storage and finally from the storage to the deep geological repository for final disposal.

The operator of the NPPs in the Czech Republic has selected "dry" storage technology in dual-purpose (storage and transport) casks. The storage casks are stored in a specifically designed building which protects the casks from adverse weather conditions. The dry storage technology was selected under time pressure in the first half of the 1990s, when, after the break-up of Czechoslovakia, it was necessary to transport back from Slovakia the SF irradiated at NPP Dukovany, which was at that time being stored in wet technology SF storage in Slovakia. Cask technology can be implemented more quickly, and therefore this technology was chosen despite being more expensive.

Cask technology involves the following costs:

- Storage building construction costs - including the preparatory phase (siting, licensing, selection of a constructor)

- Cask purchasing costs - for the life time of NPP this is a multi-billion CZK cost item - the major element in the storage costs

- Storage operation costs - personnel, energy, maintenance, insurance, technical assistance and research. During simultaneous operation with NPP those costs are not high, as many costs items are shared with NPP, and some are not required (e.g. insurance).

Currently two SF storages are in operation at NPP Dukovany. The first storage (60 casks, i.e. $600 \mathrm{t}$ of heavy metal) was put into operation in the mid 1990s. Its capacity was exhausted in 2006. When it was constructed, its capacity was limited by a political decision, due to the reluctance of the neighboring communities to accept storage for the full life time of NPP Dukovany. At that time central storage for all Czech NPPs was under consideration. However this concept was later abandoned and a second storage for (132 casks, i.e. 1340 tHM) was put into operation in 2006. This storage was planned to absorb SF production for a 40-year life time. Due to improvements in the fuel cycle (a reduced number of loaded fuel assemblies), the storage is sufficient for roughly 45-year operation of NPP Dukovany. For Option 1and Option 2, it is therefore necessary to include the cost of building additional storage.

For the purposes of an economic evaluation, the following storage costs (cash-flow view), based on 2006 fixed prices were considered:

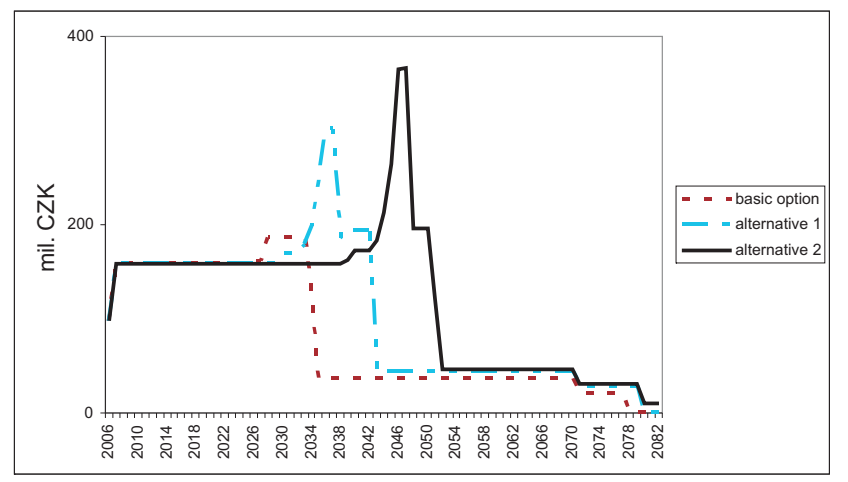

Fig. 3: Storage costs (cash-flow view) for the evaluated model NPP life time options

The same cash-flow expenses are shown on a cumulative basis in the following graph:

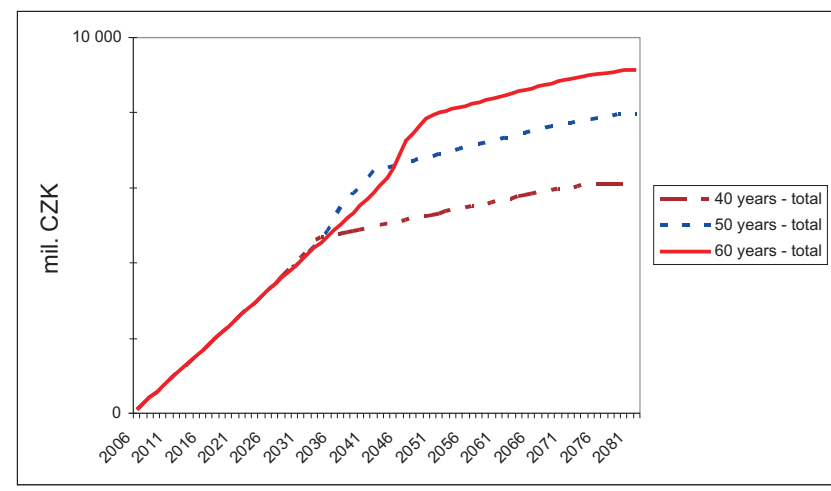

Fig. 4: Cumulative storage costs (cash-flow view) for the evaluated model NPP life time options

These cost estimates were used as one of inputs for an overall economic evaluation of the life time options. The results show that in terms of storage costs, the extension project is efficient.

In terms of liability, the situation is different. The liability to store a fuel assembly (FA) arises at the moment when the particular FA is loaded into the reactor. Before this loading, a fresh FA can be de-fabricated and individual components (nuclear material, zirconium and stainless steel structural parts) can be sold, and therefore there is no liability to store such FA

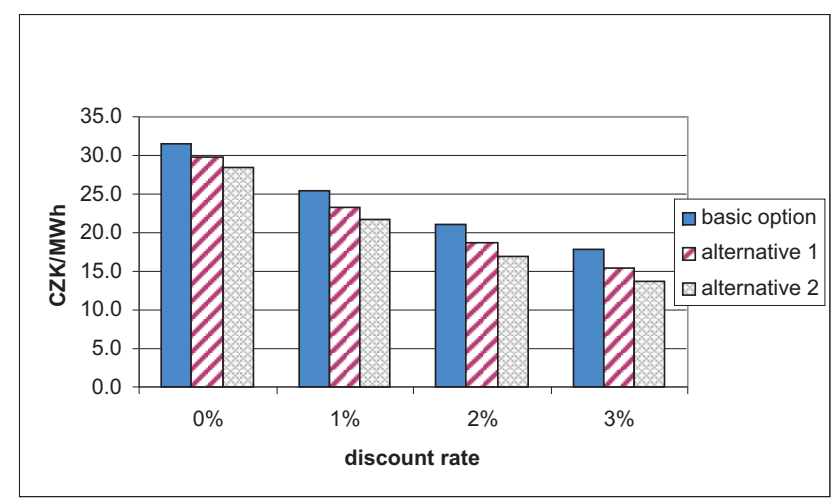

Fig. 5: Unit storage costs per generated MWh for the considered options, calculated by NPV as a function of the discount rate 
in the form of SF. However once an FA is exposed to a chain reaction its nuclear properties become such that it must be safely stored for a long time, and later disposed of. Liability is always to be assessed on the basis of the actual quantity of SF.

Consequently there is no direct link between the adopted planned NPP life time (or the decision to build a new NPP) and the financial expression of the storage liability (under the IAS 37 accounting standard) in the operator's balance of accounts. This liability is increased only if new fresh fuel is loaded into the reactor, if the or future costs estimate is updated upwards. On the other hand, the liability is decreased when the related expenses are paid (new cask, operational costs).

If SF generation reaches such a level that there is not sufficient capacity for placing the casks with SF, there will be a sudden increase in liability due to the need to build a new storage building.

As far as RW storage is concerned, there is no particular liability to be assessed. There are no explicit storage costs for items being stored for future disposal. Unlike the disposal and decommissioning liability there is no obvious relation between NPP life time (waste volume produced) and liability.

\subsection{Spent fuel \& radioactive waste disposal}

As noted earlier, SF and RW disposal is the responsibility of the state. At the present time 50 CZK per MWh generated in an NPP is paid by the operator into the nuclear account (NA). The accumulated payments together with earnings from the investment income, should cover all future costs of $\mathrm{SF}$ and RW disposal.

The assessment of the operator's liability is currently based on the legal requirement to make regular payments into the NA 50 CZK per each MWh generated at an NPP for the rest of the life time of the NPP. This duty of the operator is defined by Government Decree No. 416/2002 Coll.

The fee paid to the NA was calculated on the basis of an estimate of the costs for a deep geological repository. The capacity of this repository and the disposal time schedule were based on NPP Dukovany and NPP Temelín operating for a maximum of 40 years. These assumptions are included in the Czech Republic's strategy for SF and RW disposal.

In the event, that the operator officially decides to extend the life time of its NPP (or to build a new NPP), such a decision must first be approved by the state. Then the state will have to modify and adjust its SF and RW disposal strategy. The updated repository cost estimates, the increased amount of electricity, and the new time schedule for repository operation will be used for recalculating the fee to be paid per MWh generated at the NPP. When the new fee is calculated and a new government decree ordering the NPP operator to pay the updated fee comes into effect, the operator's disposal liability changes as well.

For the purposes of an economic evaluation, the operator needs at least an estimate of the influence of the extended life time or the new NPP on the rate of payment to the NA. For such purposes, the operator uses its own model of future disposal costs and the NA balance. A model of the NPP Dukovany life time options has shown that the effect on the rate is rather small. This was a surprising conclusion, considering the relatively small increase in the disposal costs and the substantial increase the electricity generated. From a detailed analysis we can conclude that this is because most of the future repository will be covered from the proceeds of investing today's funds (past and current payments) in the nuclear account. Only about $16-17 \%$ of future expenditures will be covered from the operator's payments. Therefore, the additional earnings (electricity generation) and costs (additional SF and RW) do not play a substantial role when the rate is calculated. For the options considered here, the changes in the rate are in Fig. 6. The difference is very small, but it is in favour of extending the life time of NPP.

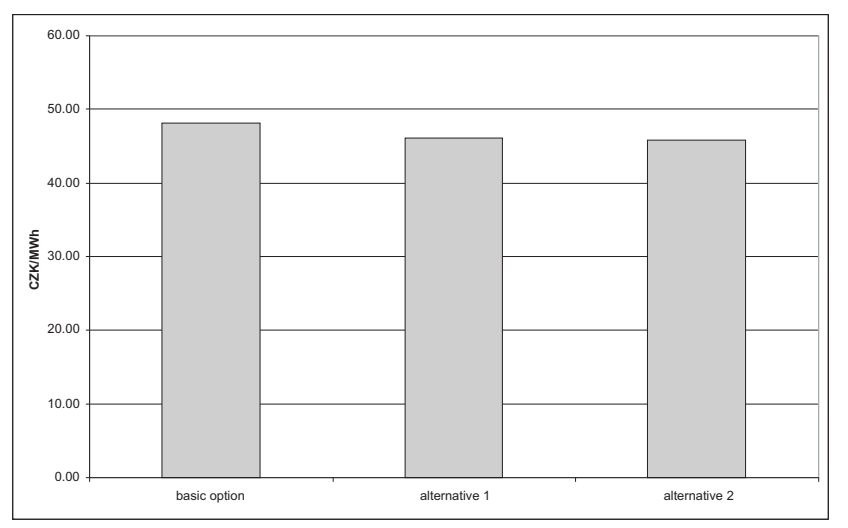

Fig. 6: Rate of the payment to the nuclear account for the evaluated options

\subsection{Decommissioning an NPP}

The operator is fully liable for decommissioning (DC) its NPP. The state only verifies the cost estimates and the availability of funds for DC (the dedicated blocked account within the assets of the NPP operator). The DC liability is assessed based on costs estimate for selected and by the Nuclear Regulatory Body (the State Office for Nuclear Safety, SONS) approved DC procedure. The costs estimate is then verified by the State Repository Authority (RAWRA). Currently the deferred DC strategy is adopted, i.e. only non-contaminated or low contaminated technology units will be dismantled. Highly activated technology units (reactor, primary circuit) will be dismantled only after a long "waiting" period (the decrease in activity during this period will reduce the doses received by the workers). The cost estimate includes expenditures for technology dismantling, removal of SF and RW, decontamination, maintenance and personnel costs during the "waiting" period.

For an economic evaluation of the NPP Dukovany life time extension options, the following cost estimates in fixed 2003 prices have been prepared. It is important to note that by adding 10 years to NPP operation the start of NPP DC is also deferred by 10 years, but the end of the DC process is fixed by the date of closure of the deep geological repository, when the highly-contaminated NPP elements will be disposed of. As a result, for the individual life time options there will be different "waiting" periods. Therefore, after 60 years of NPP operation, the highly activated elements will have less time to decrease their activity and technological adjustments will have to be made with a potential effect on the cost estimate. The final effect on DC liability (and the connected accumulation of funds) is very small and positive for the life time extension project. 
Thus, if the NPP operator declares its intention to extend the life time of its NPP, it will be necessary to make technical adjustment to the DC procedure for the different time schedule. The amended procedure must then be submitted to SONS for approval. If approval is granted, the cost estimate will have to be submitted for verification to RAWRA. When this procedure has been completed, the DC liability in the operator's balance of accounts will be re-stated. A somewhat different situation will arise if the investor declares an intention to build and put in operation a new NPP. Although preparation of the DC procedures, approval by SONS and verification of the related cost estimate are prerequisites for granting an NPP operational license, the NPP operator has no DC liability until the chain reaction in the reactor core is started for the first time.

\section{Conclusions}

For a current NPP, two options to extend its operational life time were evaluated from the point of view of additional costs related to SF storage and disposal as well as NPP decommissioning. The relevant operator liabilities were assessed. If we calculate the costs per unit of generated electricity using NPV, for the extension considered here, we can conclude that the project is efficient. However, nuclear liabilities form only one item in the very complex additional costs connected with additional investments necessary extending the operation of an NPP. The final decision must therefore be taken only when the overall evaluation has been finalized. It is not possible at this stage to anticipate the results of the overall evaluation, but as far as the back-end liabilities are concerned there is no adverse impact on the effectiveness of extending the life time of the NPP.
If the NPP operator declares a life time extension or the construction of a new NPP, there is no immediate impact on storage liability. There is also no immediate effect on disposal liability. The state, as the responsible entity, will have to amend its disposal strategy and order an amended fee per MWh generated at NPP to be paid by the operator. As far as DC liability, is concerned the effect of life time extension would be immediate, though the change in the liability can be quantified only after the amended costs estimate has been verified by RAWRA. In the case of a new NPP, a cost estimate will have to be prepared by the operator and verified by RAWRA, but there is no DC liability until the chain reaction in the reactor is started.

\section{References}

[1] Havlíček, L.: Storage Costs for Considered NPP Life Time Extension, ČEZ, a.s., Internal document, February 2007.

[2] Havlíček, L.: Modeling of Payment to the Nuclear Account, ČEZ, a.s., Analytical model KOPALC 2007, March 2007.

\footnotetext{
Ing. Ladislav Havlíček

e-mail: poster2007@radio.feld.cvut.cz havlicek.ladislav@seznam.cz

Dept. of Economics, Management and Humanities

Czech Technical University in Prague

Faculty of Electrical Engineering

Technická 2

16627 Praha, Czech Republic
} 